\title{
The Incidence and Prevalence of Multiple Sclerosis in Nova Scotia, Canada
}

\author{
Ruth Ann Marrie, John D. Fisk, Karen J. Stadnyk, Bo Nancy Yu, Helen Tremlett, \\ Christina Wolfson, Sharon Warren, Virender Bhan, for the CIHR Team in the \\ Epidemiology and Impact of Comorbidity on Multiple Sclerosis
}

\begin{abstract}
Background: Estimates of incidence and prevalence are needed to determine disease risk and to plan for health service needs. Although the province of Nova Scotia, Canada is located in a region considered to have a high prevalence of multiple sclerosis (MS), epidemiologic data are limited. Objective: We aimed to validate an administrative case definition for MS and to use this to estimate the incidence and prevalence of MS in Nova Scotia.Methods: We used provincial administrative claims data to identify persons with MS. We validated administrative case definitions using the clinical database of the province's only MS Clinic; agreement between data sources was expressed using a kappa statistic. We then applied these definitions to estimate the incidence and prevalence of MS from 1990 to 2010. Results: We selected the case definition using $\geq 7$ hospital or physician claims when $>3$ years of data were available, and $\geq 3$ claims where less data were available. Agreement between data sources was moderate (kappa $=0.56)$, while the positive predictive value was high (89\%). In 2010, the age-standardized prevalence of MS per 100,000 population was 266.9 (95\% CI: 257.1 277.1) and incidence was 5.17 (95\% CI: 3.78-6.56) per 100,000 persons/year. From 1990-2010 the prevalence of MS rose steadily but incidence remained stable. Conclusions: Administrative data provide a valid and readily available means of estimating MS incidence and prevalence. MS prevalence in Nova Scotia is among the highest in the world, similar to recent prevalence estimates elsewhere in Canada.
\end{abstract}

RÉSUMÉ: Incidence et prévalence de la sclérose en plaques en Nouvelle-Écosse, Canada. Contexte : Des estimés de l'incidence et de la prévalence sont nécessaires pour établir le risque d'une maladie et pour la planification des services de santé. Bien que la province de Nouvelle-Écosse au Canada soit située dans une région considérée comme à haute prévalence de sclérose en plaques (SP), il existe peu de données épidémiologiques à ce sujet. Objectif : Le but de l'étude était de valider une définition administrative de cas pour la SP et de l'utiliser pour estimer l'incidence et la prévalence de la SP en Nouvelle-Écosse. Méthode : nous avons utilisé des données administratives provinciales de réclamation pour identifier les individus atteints de la SP. Nous avons validé les définitions administratives de cas au moyen de la base de données cliniques de la seule clinique de SP de cette province. La concordance entre les sources de données a été évaluée au moyen du test de concordance Kappa. Nous avons ensuite appliqué ces définitions pour estimer l'incidence et la prévalence de la SP de 1990 à 2010. Résultats : Nous avons choisi la définition de cas au moyen de 7 réclamations ou plus provenant d'un hôpital ou d'un médecin quand des données couvrant une période de plus de 3 ans étaient disponibles et 3 réclamations ou plus quand moins de données étaient disponibles. La concordance entre les sources de données était modérée (kappa $=0,56$ ) et la valeur prédictive positive était élevée (89\%). En 2010, la prévalence de la SP ajustée pour l'âge par 100000 de population était de 266,9 (IC à 95\% : 257,1 à 177,1) et l'incidence était de 5,17 (IC à 95\% : 3,78 à 6,56) par 100000 de population par année. De 1990 à 2010, la prévalence de la SP a augmenté régulièrement mais son incidence est demeurée stable. Conclusions : Les données administratives fournissent des moyens valides et facilement disponibles d'estimer l'incidence et la prévalence de la SP. La prévalence de la SP en Nouvelle-Écosse est l'une des plus élevées dans le monde et elle est comparable à celle des autres régions du Canada.

Can J Neurol Sci. 2013; 40: 824-831

Multiple sclerosis (MS) is a chronic, disabling disease of the central nervous system. Prevalence and incidence are fundamental, and complementary, epidemiologic measures of disease within a population. While incidence estimates are essential for determining the risk of disease, prevalence estimates are important for establishing the burden of disease and planning health services where it is critical to understand the total number of people affected. A recent systematic review of MS incidence and prevalence studies in the Americas recognized Canadian studies as generally well-designed but identified limitations due to geographic restrictions and small samples that add uncertainty to estimates. ${ }^{1}$ Further, differences in case ascertainment, diagnostic criteria, and time periods, have compromised our ability to understand the epidemiology of MS in Canada. Like some other Canadian regions, limited data are available on MS prevalence in the province of Nova Scotia..$^{2,3}$

\footnotetext{
From the Department of Internal Medicine (RAM, BNY), Department of Community Health Sciences (RAM, BNY), University of Manitoba, Winnipeg; Department of Psychiatry (JDF), Department of Medicine (JDF, VB), Dalhousie University; Capital District Health Authority (JDF, KJS, VB), Halifax, Nova Scotia; Department of Medicine (Neurology) (HT), University of British Columbia, Vancouver, British Columbia; Department of Epidemiology and Biostatistics and Occupational Health (CW), Research Institute of the McGill University Health Centre (CW), Montreal, Quebec; Faculty of Rehabilitation Medicine (SW), University of Alberta, Edmonton, Alberta, Canada.

Received March 25, 2013. Final Revisions Submitted May 16, 2013. Correspondence to: Ruth Ann Marrie, Health Sciences Center, GF-533, 820 Sherbrook Street, Winnipeg, Manitoba, R3A 1R9, Canada. Email: rmarrie@hsc.mb.ca.
} 
Studies of MS prevalence using uniform methods are needed in high risk regions such as Canada, and should standardize for age and sex, to ensure comparability between studies and to facilitate examination of regional variations. ${ }^{1}$ In publicly funded health systems such as Canada, administrative health claims data are population-based and have been used successfully for surveillance of other chronic diseases. ${ }^{4}$ An optimal administrative case definition for MS has been validated in Manitoba, ${ }^{5}$ but included prescription claims data which are not always available elsewhere. As a result, this definition has limited generalizability as a case ascertainment method for other Canadian provinces. We aimed to validate an administrative case definition of MS without using prescription claims, and to apply this definition to estimate the incidence and prevalence of MS in Nova Scotia. Our longitudinal dataset also offered the opportunity to assess temporal trends in the incidence and prevalence of MS over a twenty year interval.

\section{MeTHODS}

Nova Scotia is an eastern Canadian province with a population of approximately 945,000 (http://www.gov.ns.ca/ finance/statistics//stats/default.asp?id=1). Our data sources included provincial administrative health claims data held by the Population Health Research Unit (PHRU) at Dalhousie University (http://www.phru.dal.ca), and medical records from patients attending the Dalhousie Multiple Sclerosis Research Unit (DMSRU). Ethical approval for this study was obtained from the Capital Health Research Ethics Board.

\section{Administrative Data}

Nova Scotia residents receive care through the publicly funded provincial Health Insurance Program. In 1993/1994, health card identification numbers were reassigned as "lifetime" unique personal numbers for each Nova Scotia resident; this number is attached to each health service claim. Persons who moved out of province or died before this reassignment did not have their health card number reassigned. Within the Health Insurance Program, the Insured Patient Registry captures sex, date of birth, and dates of coverage and death for each beneficiary of provincial health services. Fee-for-service physicians submit a claim with the patient's identification number, date of service, and a 3-digit International Classification of Disease (ICD)-9 code for the assigned diagnosis. Most salaried physicians also shadow bill. ${ }^{6}$ Between 1989 and 1996 physicians could submit only one diagnosis per claim, but as of 1997 could submit up to three diagnoses. Because some Canadian jurisdictions submit only one diagnosis per physician claim, we used only the primary (first) diagnosis submitted for each physician claim. Before 2001, hospital discharge abstracts records used 5-digit ICD-9 codes, but subsequently used ICD10-CA codes. For hospital admissions, we used all available diagnoses. Prescription claims data were not used.

In 2008, we used administrative claims data from Manitoba to identify persons with demyelinating disease using ICD9/ICD-10 diagnostic codes and prescription claims. ${ }^{5}$ To validate candidate case definitions, questionnaires were mailed to 2000 randomly selected persons with an encounter for demyelinating disease, requesting permission for medical records review. Using a standardized form and trained reviewers, we reviewed medical records, including clinic notes and reports of diagnostic testing (imaging, cerebrospinal fluid, evoked potentials), and used these as the standard to evaluate candidate case definitions using administrative data. As done in Manitoba, ${ }^{5}$ we searched Nova Scotia hospital and physician claims from January 1, 1990 to December 31, 2010 for diagnostic codes (ICD-9/ICD-10-CA) for demyelinating diseases of the CNS, including optic neuritis (377.3/H46), acute transverse myelitis (323.82/G37), acute disseminated encephalomyelitis (323/G36.9), demyelinating disease of CNS unspecified (341.9/G37.8), other acute disseminated demyelination (G36), MS (340/G35), and neuromyelitis optica (341.0/G36.0). Also as before, we created several potential case definitions, varying the number of physician and hospital claims, and the years of data required to classify a person as having MS.

\section{Dalhousie Multiple Sclerosis Research Unit (DMSRU) Database}

The DMSRU is the only provincial outpatient clinic specializing in MS care in Nova Scotia. It has a clinical database that was established in 1980. Since 1998, the DMSRU has been the sole provider for disease-modifying therapies in Nova Scotia. As a result, new and suspected MS cases are referred for evaluation and those on therapy are required to be re-evaluated on an approximately annual basis. Those who are older, or disabled, or not requiring neurologic follow-up are less likely to attend the clinic currently but may be registered in the database as a result of past attendance. ${ }^{7}$ Each patient visit has been documented systematically since 1980 , including those in whom the diagnosis of MS was ultimately refuted. Diagnoses are updated at each clinic visit using standardized data collection forms, and are classified as definite/probable MS, possible MS or not MS according to the prevailing diagnostic criteria as of the date of that visit. ${ }^{8-11}$ Patients attending the DMSRU consent to linkage of their clinical and administrative data for research.

\section{Incidence and Prevalence}

We compared the classification of MS cases according to the administrative case definitions and to DMSRU diagnoses by computing sensitivity, specificity, positive (PPV) and negative predictive value (NPV), as well as Youden's J, an index that equally weights sensitivity (Se) and specificity (Sp), calculated as: $(\mathrm{Se}+\mathrm{Sp})-1 .{ }^{12} \mathrm{We}$ estimated agreement using a kappa $(\mathrm{k})$ statistic. We interpreted $\mathrm{k}$ as: slight $(0-0.20)$, fair (0.21-0.40), moderate (0.41-0.60), substantial (0.61-0.80), and almost perfect agreement (0.81-1.0). ${ }^{13}$ We then applied three preferred case definitions to estimate the prevalence and incidence of MS. Those meeting the MS case definition were considered to be affected from the date of their first demyelinating disease diagnostic code, as listed above. Prevalence of MS was estimated annually using the mid-year population figures for denominators. To estimate incidence we required a five year runin period preceding the first demyelinating disease claim to ensure that cases were truly incident; 1995 was the first year we could establish an incident case. We used the direct method to age-standardize the results to the 2001 Canadian population to be consistent with prior work, ${ }^{5}$ and calculated $95 \%$ confidence 
intervals (CI) assuming a Poisson distribution. Statistical analyses used SAS V9.1 (SAS Institute Inc., Cary, NC).

\section{RESUlts}

Over the twenty year study period, the administrative data yielded a cohort of 8445 persons with $\geq 1$ demyelinating disease claims from a total population of $19,302,827(0.034 \%)$. The DMSRU captured 4285 persons, of whom 3805 (88.8\%) were linked successfully to administrative claims data. Of those linked, 2773 (72.9\%) had definite or probable MS, 509 (13.4\%) had possible MS and 523 (18.9\%) did not have MS. All DMSRU cases had at least one demyelinating disease claim. Of 5071 Nova Scotia residents with $\geq 2$ MS claims, 3384 (66.7\%) were evaluated in the DMSRU, while 3174 (74.4\% of 3174) of those with $\geq 3$ MS claims were evaluated, 2901 (80.4\% of 3606) of those with $\geq 5$ MS claims were evaluated, and 2687 (83.1\% of 3232) with $\geq 7$ MS claims were evaluated. Thus most Nova Scotians with repeated health care contacts for MS had been evaluated in the DMSRU.

Initially, we classified persons with possible MS (based on DMSRU data as of December 31, 2010) as having MS, given that some could ultimately be diagnosed with MS (Group 'A' clinical case definitions). ${ }^{14}$ As the number of required health care contacts (hospitalizations or physician visits) increased, the sensitivity of the administrative case definition as compared to the clinical case definition decreased, while the specificity increased (Supplemental Table 1). The administrative case definition which required $\geq 7$ hospital or physician claims was the least sensitive (78\%; 95\% CI: 77-80\%) but most specific (77\%; 95\% CI: 73-81\%) and had the highest PPV (95\%; 95\% CI: 94$96 \%)$. The PPV for the case definition which required $\geq 5$ hospital or physician claims was similar (95\%; 95\% CI: $94-$ 96\%).

When we re-classified persons with possible MS as not having MS (Group 'B' clinical case definitions, Supplemental Table 1) the sensitivity of the administrative case definitions increased slightly, the specificity decreased, the PPVs tended to be slightly lower and the NPVs were higher. Agreement, as measured by kappa, also increased and was moderate for definitions requiring $\geq 3,5$ or 7 claims ( $k=0.50-0.54$ ). Finally we excluded the individuals with possible MS (Group ' $\mathrm{C}$ ' case definitions, Supplemental Table 1) which resulted in similar findings as for Group 'B', except with higher PPV and lower NPV.

We further stratified the analysis for Group 'A' clinical case definitions according to whether $\leq 3$ or $>3$ years of administrative data were available. For individuals with $>3$ years of data, the sensitivity of the definition which used $\geq 7$ claims was $82 \%$ (Supplemental Table 2), decreasing slightly to $78 \%$ when applied to all individuals (Supplemental Table 1) and substantially (to $37 \%$ ) when applied to individuals with $\leq 3$ years of data. The specificity was similar when applied to individuals with $>3$ years of data $(75 \%)$ or to all individuals $(77 \%)$, but much higher for individuals with $\leq 3$ years of data (100\%). Based on these findings we created a 'combined' administrative case definition which required $\geq 3$ claims for individuals with $\leq 3$ years of data and $\geq 7$ hospital or physician claims for individuals with $>3$ years of data. This combined definition had a sensitivity of $88 \%$ (95\% CI: $87-90 \%$ ), specificity of $68 \%$ (95\% CI: $65-$ $71 \%$ ), PPV of $89 \%$ (95\% CI: $88-90 \%)$, NPV of $67 \%$ (95\% CI: 64-70\%), and kappa of 0.56 (95\% CI: 0.53-0.59).

To illustrate the impact of differing administrative case definitions on estimates of incidence and prevalence, we selected three definitions for further analysis: (i) Definition A2.: $\geq 3$ hospital or physician claims using all available data (sensitive but less specific definition); (ii) Definition A4.: $\geq 7$ hospital or physician claims using all available data (specific but less sensitive definition); and (iii) 'Combined' Definition: $\geq 3$ hospital or physician claims for individuals with $\leq 3$ years of data available and $\geq 7$ hospital or physician claims for individuals with $>3$ years of data.

\section{Incidence}

Over the period 1995 to 2010 , the average annual rate per 100,000 population applying the 'combined' definition was 9.77 (95\% CI: 8.00-11.9) (Table 1). The annual incidence rate was stable, with a change in incidence of -0.36 (95\% CI: $-0.56-$ -0.17 ) per 100,000 population per year (Figure 1). Applying the

Table 1: Average Annual Incidence (Inc) of Multiple Sclerosis in Nova Scotia per 100,000 population by age and sex, $1995-2010$

\begin{tabular}{|c|c|c|c|c|c|c|c|c|c|c|c|}
\hline \multirow{2}{*}{$\begin{array}{c}\text { Age } \\
\text { (years) }\end{array}$} & \multicolumn{3}{|c|}{ Women } & \multicolumn{3}{|c|}{ Men } & \multicolumn{2}{|c|}{ Women: Men } & \multicolumn{3}{|c|}{ Both } \\
\hline & No. Cases & Inc. & $95 \%$ CI & No. Cases & Inc. & $95 \%$ CI & Rate Ratio & $95 \%$ CI & No. Cases & Inc. & $95 \%$ CI \\
\hline$\leq 24^{*}$ & 53 & 2.43 & $0.86,6.89$ & 16 & 0.70 & $0.10,4.65$ & 3.48 & $0.40,30.3$ & 69 & 1.54 & $0.62,3.84$ \\
\hline $25-29$ & 86 & 17.5 & $7.74,39.8$ & 24 & 5.07 & $1.08,23.9$ & 3.46 & $0.60,19.9$ & 110 & 11.4 & $5.54,23.5$ \\
\hline $30-34$ & 157 & 29.6 & $16.2,54.3$ & 30 & 5.96 & $1.49,23.8$ & 4.97 & $1.10,22.6$ & 187 & 18.1 & $10.4,31.5$ \\
\hline $35-39$ & 186 & 32.0 & $18.3,55.8$ & 51 & 9.23 & $3.19,26.7$ & 3.46 & $1.04,11.5$ & 237 & 20.9 & $12.8,34.2$ \\
\hline $40-44$ & 208 & 34.4 & $20.3,58.3$ & 62 & 10.7 & $4.08,28.0$ & 3.22 & $1.07,9.66$ & 270 & 22.8 & $14.4,36.2$ \\
\hline $45-49$ & 162 & 27.4 & $15.1,49.7$ & 60 & 10.4 & $3.92,27.8$ & 2.62 & $0.83,8.26$ & 222 & 19.0 & $11.4,31.7$ \\
\hline $50-54$ & 99 & 18.6 & $6.68,39.9$ & 59 & 11.3 & $4.21,30.4$ & 1.64 & $0.47,5.73$ & 158 & 15.0 & $8.20,27.4$ \\
\hline $55-59$ & 61 & 13.5 & $5.10,35.6$ & 28 & 6.28 & $1.50,26.3$ & 2.14 & $0.38,12.1$ & 89 & 9.90 & $4.43,22.1$ \\
\hline$\geq 60^{*}$ & 62 & 3.94 & $1.50,10.3$ & 37 & 2.91 & $0.84,10.1$ & 1.35 & $0.28,6.55$ & 99 & 3.48 & $1.62,7.46$ \\
\hline Total & 1074 & 14.2 & $11.3,18.0$ & 367 & 5.09 & $3.42,7.56$ & 2.80 & $1.77,4.43$ & 1441 & 9.77 & $8.00,11.9$ \\
\hline
\end{tabular}




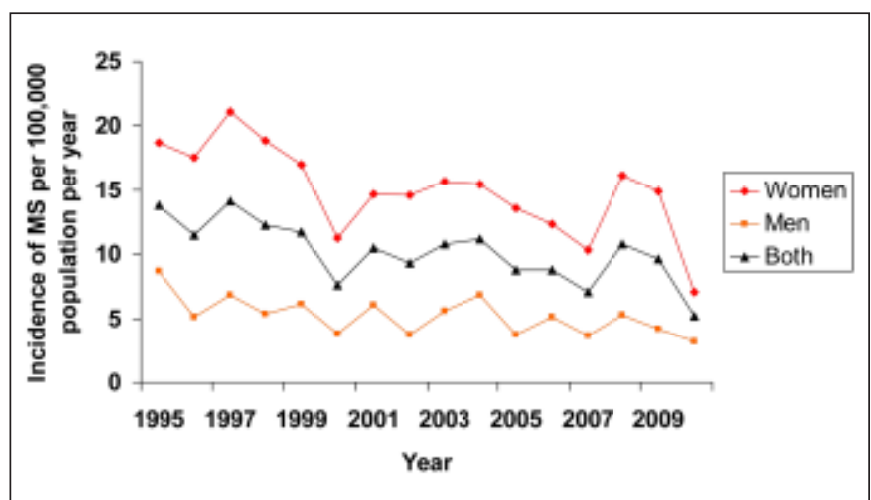

Figure 1: Incidence of multiple sclerosis per 100,000 persons per year in Nova Scotia, Canada from 1995-2010.

sensitive definition, the change in incidence was -0.57 (95\% CI: $-0.84--0.30$ ), and applying the specific definition the change in incidence was -0.66 (95\% CI: -0.87- -0.44). Some year-to-year variation was evident, including an apparent small increase in incidence rate around 1997 when the annual incidence rate reached 14.1 (95\% CI: 11.8-16.5) per 100,000 population (Figure 1). The incidence of MS was three-fold higher among women than men, peaking at age 40-44 years among women, and 50-54 years among men (Table 1). Over the period 19951999, the female: male incidence ratio was 2.99 , while it was 2.86 in 2000-2004, and 3.11 in 2005-2010.

\section{Prevalence}

In 2010, the crude prevalence of MS per 100,000 population ranged from 251.5 (95\% CI: 241.9-261.3) for Definition 'A4' (specific) to 326.3 (95\% CI: 315.4.3-337.5) for Definition 'A2' (sensitive), with the crude prevalence for the 'combined'

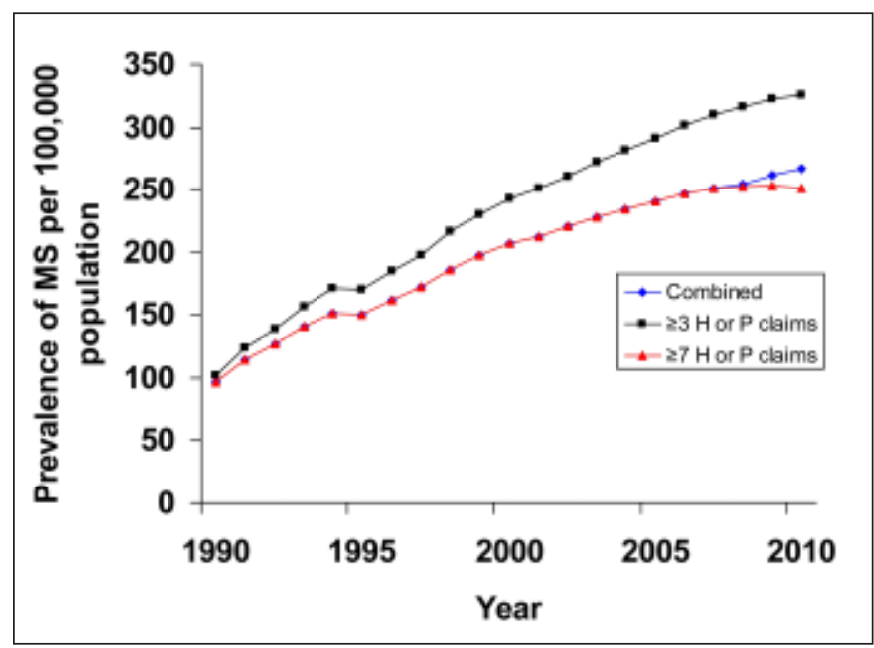

Figure 2: Age-standardized prevalence of multiple sclerosis per 100,000 population in Nova Scotia, Canada from 1991-2010.

definition falling between the two (266.9; 95\% CI: 257.0-277.1). Using this 'combined' definition, the age-standardized prevalence in 2010 was 266.9 (95\% CI: 256.9-276.8). Regardless of the case definition used, prevalence increased steadily from 1990 onward (Figure 2), increasing by 8.28 (95\% CI: 7.70-8.86) annually for the combined definition, 11.2 (95\% CI: 10.6-11.9) for the specific definition ('A4'), and 7.96 (95\% CI: 7.21-8.71) for the sensitive definition ('A2').

Over time, the peak age-specific prevalence shifted from 4549 years in 1990 to 55-59 years in 2010 (Figure 3, Table 2). Although the prevalence declined after age 60 in all years, in 2010 it still remained relatively high, with 350 persons affected per 100,000 population. The age-standardized prevalence of MS

Table 2: Prevalence with 95\% confidence interval (CI) of Multiple Sclerosis in Nova Scotia per 100,000 population in 2010 stratified according to age and sex

\begin{tabular}{|c|c|c|c|c|c|c|c|c|c|}
\hline \multirow[b]{2}{*}{ Age (Years) } & \multicolumn{3}{|c|}{ Women } & \multicolumn{3}{|c|}{ Men } & \multicolumn{3}{|c|}{ Both } \\
\hline & Prevalence & $\begin{array}{c}\text { Lower } 95 \% \\
\text { CI }\end{array}$ & $\begin{array}{c}\text { Upper } 95 \% \\
\text { CI }\end{array}$ & Prevalence & $\begin{array}{c}\text { Lower } 95 \% \\
\text { CI }\end{array}$ & $\begin{array}{c}\text { Upper } 95 \% \\
\text { CI }\end{array}$ & Prevalence & $\begin{array}{c}\text { Lower } 95 \% \\
\text { CI }\end{array}$ & $\begin{array}{c}\text { Upper } 95 \% \\
\text { CI }\end{array}$ \\
\hline $0-24$ & 7.4 & 4.0 & 13.7 & 2.1 & 0.7 & 6.4 & 4.6 & 2.7 & 8.0 \\
\hline $25-29$ & 110.7 & 79.9 & 153.5 & 37.1 & 21.1 & 65.4 & 74.0 & 55.8 & 98.3 \\
\hline $30-34$ & 283.1 & 231.1 & 347.0 & 76.1 & 51.0 & 113.6 & 181.8 & 151.7 & 217.9 \\
\hline $35-39$ & 338.0 & 282.4 & 404.5 & 102.4 & 73.5 & 142.6 & 221.9 & 189.5 & 259.9 \\
\hline $40-44$ & 612.5 & 537.5 & 698.0 & 154.7 & 118.7 & 201.4 & 387.3 & 344.5 & 435.4 \\
\hline $45-49$ & 790.0 & 710.4 & 878.4 & 199.7 & 161.3 & 247.4 & 498.7 & 453.5 & 548.4 \\
\hline $50-54$ & 849.7 & 766.1 & 942.5 & 259.7 & 214.7 & 314.2 & 559.4 & 510.7 & 612.7 \\
\hline $55-59$ & 863.4 & 775.0 & 961.9 & 264.6 & 216.8 & 322.8 & 569.8 & 518.2 & 626.5 \\
\hline $\begin{array}{l}\geq 60 \\
\text { Age- }\end{array}$ & 455.2 & 419.3 & 494.2 & 226.6 & 199.7 & 257.1 & 350.0 & 326.7 & 375.0 \\
\hline standardized & 399.0 & 382.2 & 416.5 & 130.3 & 120.7 & 140.7 & 266.9 & 257.1 & 277.1 \\
\hline
\end{tabular}


was higher in women (399.0 [95\% CI: 382.2-416.5]) than men (130.3 [95\% CI: 120.7-140.7]).

\section{INTERPRETATION}

We demonstrated health administrative data to be a useful, valid information source for the surveillance of both the incidence and prevalence of MS. Using the best administrative case definition for MS, the crude prevalence was 266.9 (95\% CI: 257.0-277.1) and average annual incidence was 9.77 per 100,000 population.

In 1960, a study of a single Nova Scotia county reported a prevalence of MS of only $32.4 / 100,0000^{2,3}$ The only other prevalence estimates for this region used self-report data from the 2000/2001 Canadian Community Health Survey but due to the small number of respondents, only a single prevalence of estimate of 350 per 100,000 (95\% CI: 230-470) was reported for all Atlantic Canadian provinces, including Nova Scotia. ${ }^{15}$ Our estimate falls within the bounds of that estimate. In the last five years, three prevalence studies from western Canada have reported crude prevalence estimates of $\geq 260$ per 100,000 population. ${ }^{16-18}$ The average annual incidence of MS in Nova Scotia was 9.77 per 100,000 population; similar to that in Manitoba over the period 1984 to 2005,5 and in Saskatoon, Saskatchewan over the period 1970 to $2004 .{ }^{16}$ In Alberta the incidence is higher, ranging from 20.9 to 23.9 per 100,000 population for the period 1990 to $2004 .{ }^{18}$ Overall, incidence rates in Canada appear similar to those for Europe. ${ }^{19}$

We found that MS prevalence increased over the twenty year study period, but that incidence was stable. Since prevalence is a function of incidence and disease duration, this may reflect earlier diagnosis, improved survival, or both. ${ }^{18}$ Several studies suggest the diagnostic delay for MS is decreasing. ${ }^{5,20}$ Our observed rightward shift in peak age-specific prevalence suggests that improved survival ${ }^{17}$ is also influencing MS prevalence. Given the better availability of magnetic resonance imaging and changes in diagnostic criteria aimed at facilitating earlier diagnosis, and possibly leading to the identification of milder cases, the stable incidence may seem surprising. However, stable MS incidence was also found in Manitoba using administrative data covering a similar time period. This finding is also consistent with those reported in Newfoundland and Labrador $^{21}$ and in Saskatoon, Saskatchewan ${ }^{16}$ using different methods. We did observe transient fluctuations in incidence and they may reflect changes in ascertainment due to local factors. For example, the increased incidence in 1997 coincided with the advent of publicly funded disease-modifying therapies, likely making (timely) diagnosis more important. Such findings illustrate the importance of evaluating trends in incidence over extended periods of time and the need to carefully consider factors that may influence ascertainment.

The female predominance of MS has well-recognized for many years. Over a fifteen year period from 1995 to 2010 we observed that women had a nearly three-fold increased incidence of MS when compared to men. This is consistent with findings reported in Saskatoon, Saskatchewan where the female to male incidence ratio was 2.6 in $1990-1999$, and 2.9 in $2000-2004 .{ }^{16} \mathrm{~A}$ systematic review of temporal trends in the incidence of MS, among other studies, suggested that the sex ratio is rising 22 although we did not observe this increase in the sex ratio.

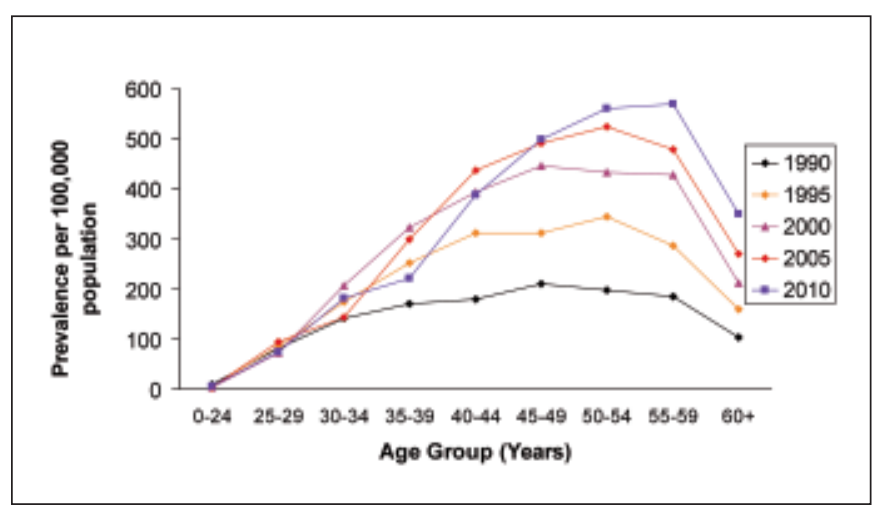

Figure 3: Age-Specific Prevalence of Multiple Sclerosis in Nova Scotia per 100,000 Population by Year between 1990 and 2010.

However, the preferred study design for evaluating such trends is to compare ratios in birth cohorts who have passed through most, if not all, of their lifetime period of disease risk. This eliminates the problems imposed by differential ages of symptom onset by sex, and by incomplete ascertainment of cases with later symptom onset. A recent study from Sweden that used such birth cohorts for persons with MS born between 1931 and 1985, also failed to find a change in sex ratio over time. ${ }^{23}$

The optimal administrative case definition for MS varied somewhat with the number of years of data available. Among persons with three or fewer years of data, $\geq 3$ claims for MS had a PPV of $95 \%$. Among persons with more than three years of data, the presence of $\geq 7$ claims for MS had a PPV of $95 \%$. The specificity and NPV reported for these case definitions were based on their application in a population with at least one claim for demyelinating disease. Given that only $0.034 \%$ of the population had even one such claim these case definitions have a specificity of $>99 \%$ in the general population. This supports the use of administrative data for the surveillance of MS incidence and prevalence in Nova Scotia while the similar performance of administrative case definitions in Manitoba ${ }^{5}$ suggests that the use of such methods for national surveillance is feasible. The only other validated administrative case definition for MS used Veterans Health Administration data in the United States. It had a sensitivity of $93 \%$ and specificity of $92 \%$, and required $\geq 1$ health care encounter for MS for each year of data available. ${ }^{24}$

Ours was a population-based study, and we had a large welldefined clinical cohort in which to validate our case definitions. Although administrative data could miss persons with MS who were not followed by a physician, the extended study period makes this unlikely. Nonetheless, we have probably underestimated the incidence of MS in the final study years since multiple health claims are required for the case definition. Thus cautious interpretation is needed for incidence rates in more recent years although this does not affect interpretation of the early-mid study years' data. The number of persons with MS under age 24 years and over age 60 years was too small to allow for detailed analyses of these age groups due to confidentiality considerations. 
Our findings demonstrate that administrative data are a valid means of estimating MS incidence and prevalence in Canada. Furthermore, our findings suggest that cost-effective methods can be developed to allow use of administrative data for this purpose. Consistent, unbiased collection of administrative data over extended periods of time provides the information necessary to evaluate temporal trends in incidence and prevalence. These can reflect and guide policies influencing ascertainment and service provision. Our prevalence estimates of MS in Nova Scotia are among the highest in the world, but importantly, are similar to recent estimates elsewhere in Canada. Evidence for increasing prevalence implies an increasing societal burden of MS in Canada. The shift in age-specific peak prevalence over the 20 year observation period points to the need to consider MS as a chronic disease of late middle age and older. It also illustrates the importance of examining factors that may be associated with poor health outcomes in later life ${ }^{25}$ and those associated with aging well with MS. ${ }^{26}$

\section{CIHR TEAM}

CIHR Team in the Epidemiology and Impact of Comorbidity on Multiple Sclerosis (by site): University of Manitoba (James Blanchard MD, PhD; Patricia Caetano, PhD; Lawrence Elliott, MD, MSc; Stella Leung, MSc; Ruth Ann Marrie, MD, PhD; Bo Nancy Yu, MD, PhD) Dalhousie University (Virender Bhan, MBBS; John D. Fisk, PhD), University of Alberta (Joanne Profetto-McGrath, PhD; Sharon Warren, PhD; Larry Svenson, BSc); McGill University (Christina Wolfson, PhD); University of British Columbia (Helen Tremlett, PhD); University of Calgary (Scott Patten, MD, PhD)

\section{ACKNOWLEDGEMENT}

This study was supported (in part) by Don Paty Career Development grants (to RAM) from the Multiple Sclerosis Society of Canada, the Canadian Institutes of Health Research, and the Rx \& D Health Research Foundation. The funding source(s) had no role in the study design, collection, analysis or interpretation of the data, or in the decision to submit the article for publication. The results and conclusions presented are those of the authors.

\section{CONFLICT OF INTEREST}

Ruth Ann Marrie receives research funding from: Canadian Institutes of Health Research, Public Health Agency of Canada, Manitoba Health Research Council, Health Sciences Centre Foundation, Multiple Sclerosis Society of Canada, Multiple Sclerosis Scientific Foundation, Rx \& D Health Research Foundation, and has conducted clinical trials funded by Bayer Inc. and Sanofi-Aventis.

John Fisk is the Director of the endMS Atlantic Regional Research and Training Centre which is funded by the Multiple Sclerosis Society of Canada. He receives research funding from the Canadian Institutes of Health Research (CIHR) and in the past has received grants, honoraria and consultation fees from AstraZeneca, Bayer, Biogen-Idec Canada, Heron Evidence Development Limited, Hoffmann-La Roche, MAPI Research Trust, Novartis, Sanofi-Aventis, Serono Canada, and QualityMetric Incorporated.

Nancy $\mathrm{Yu}$ receives research support from the Canadian International Development Agency, the Multiple Sclerosis Society of Canada, CIHR, and Manitoba Health and Healthy Living.

Helen Tremlett currently receives funding from: the Multiple Sclerosis Society of Canada [Don Paty Career Development Award]; US National MS Society [\#RG 4202-A-2 (PI)]; Canadian Institutes of Health Research [MOP: \#190898 (PI) and MOP-93646 (PI)]; Michael Smith Foundation for Health Research (Scholar award) and the Canada Research Chair program. She has received speaker honoraria and/or travel expenses to attend conferences from: the Consortium of MS Centres, US National MS Society, Swiss Multiple Sclerosis Society, the University of British Columbia Multiple Sclerosis Research Program, Teva Pharmaceuticals, Novartis Canada and Bayer Pharmaceutical (honoraria declined) and ECTRIMS. Unless otherwise stated, all speaker honoraria are either donated to an MS charity or to an unrestricted grant for use by her research group.

Christina Wolfson receives research funding from the Multiple Sclerosis Society of Canada, National Multiple Sclerosis Society, Canadian Institutes of Health Research, Canada Foundation for Innovation, and Public Health Agency of Canada.

Sharon Warren receives research funding from the CIHR, the Canadian Health Services Research Foundation, Alberta Health Services and SSHRC.

Virender Bhan receives research funding from the CIHR, and has acted as advisor/consultant for Bayer, Biogen Idec, EMD Serono, Novartis, and Teva Pharmaceutical Industries. 


\section{REFERENCES}

1. Evans C, Beland S, Kulaga S, et al. Incidence and prevalence of multiple sclerosis in the Americas: a systematic review. Neuroepidemiology. 2013;40(3):195-210.

2. Allison RS. Geographic distribution of multiple sclerosis. Preliminary notes on a comparative study of prevalence in Charleston, S.C. and Halifax, N.S. Acta Psychiatrica Scandinavica Suppl. 1960;35(147):18-22.

3. Alter M, Talbert OR, Allison RS, Kurland LT. The geographic distribution of multiple sclerosis. A comparative study in Charleston County, South Carolina and Halifax County, Nova Scotia. I. Prevalence in Charleston County, South Carolina. J S C Med Assoc. 1960;56:209-13.

4. Patten S. Integrating data from clinical and administrative databases in pharmacoepidemiological research. Can J Clin Pharmacol. 1998;5(2):92-7.

5. Marrie RA, Yu N, Blanchard JF, Leung S, Elliott L. The rising prevalence and changing age distribution of multiple sclerosis in Manitoba. Neurology. 2010;74(6):465-71.

6. Canadian Institute for Health Information. Physicians in Canada: The status of Alternative Payment Programs 2005-2006. Ottawa: CIHI; 2008.

7. Sketris I, Hicks V, Brown MJ, et al. Multiple sclerosis diseasemodifying drug utilization patterns following introduction of a provincially funded program in Nova Scotia, Canada, 19982004. J Appl Ther Res. 2011;8(2):65-78.

8. Polman $\mathrm{CH}$, Reingold SC, Edan G, et al. Diagnostic criteria for multiple sclerosis: 2005 revisions to the "McDonald Criteria". Ann Neurol. 2005;58(6):840-6.

9. McDonald WI, Compston A, Edan G, et al. Recommended diagnostic criteria for multiple sclerosis: Guidelines from the international panel on the diagnosis of multiple sclerosis. Ann Neurol. 2001;50(1):121-7.

10. Poser CM, Paty DW, Scheinberg L, et al. New diagnostic criteria for multiple sclerosis: Guidelines for research protocols. Ann Neurol. 1983;13(3):227-31.

11. Polman CH, Reingold SC, Banwell B, et al. Diagnostic criteria for multiple sclerosis: 2010 Revisions to the McDonald criteria. Ann Neurol. 2011;69(2):292-302.

12. Youden WJ. Index for rating diagnostic tests. Cancer. 1950:32-5.

13. Landis JR, Koch GG. The measurement of observer agreement for categorical data. Biometrics. 1977;33(1):159-74.

14. Miller DH, Chard DT, Ciccarelli O. Clinically isolated syndromes. Lancet Neurol. 2012;11(2):157-69.

15. Beck CA, Metz LM, Svenson LW, Patten SB. Regional variation of multiple sclerosis prevalence in Canada. Mult Scler. 2005;11(5): 516-9.

16. Hader WJ, Yee IML. Incidence and prevalence of multiple sclerosis in Saskatoon, Saskatchewan. Neurology. 2007;69(12):1224-9.

17. Marrie R, Yu B, Leung S, et al. Rising prevalence of vascular comorbidities in MS: validation of administrative definitions for diabetes, hypertension, hyperlipidemia. Mult Scler. 2012;18(9):1310-9.

18. Warren SA, Svenson LW, Warren KG. Contribution of incidence to increasing prevalence of multiple sclerosis in Alberta, Canada. Mult Scler. 2008;14(7):872-9.

19. Fromont A, Binquet C, Sauleau E, et al. National estimate of multiple sclerosis incidence in France (2001-2007). Mult Scler. 2012;18(8):1108-15

20. Modrego PJ, Pina MA. Trends in prevalence and incidence of multiple sclerosis. J Neurol Sci. 2003;216:89-93.

21. Sloka JS, Pryse-Phillips WEM, Stefanelli M. Incidence and prevalence of multiple sclerosis in Newfoundland and Labrador. Can J Neurol Sci. 2005;32:37-42.

22. Alonso A, Hernan MA. Temporal trends in the incidence of multiple sclerosis: A systematic review. Neurology. 2008;71(2): 129-35.

23. Bostrom I, Stawiarz L, Landtblom A-M. Sex ratio of multiple sclerosis in the National Swedish MS Register. Mult Scler. 2013; 19(1):46-52.
24. Culpepper WJ, Ehrmantraut M, Wallin MT, Flannery K, Bradham DD. Veterans Health Administration multiple sclerosis surveillance registry: The problem of case-finding from administrative databases. J Rehabil Res Dev. 2006;43(1):17.

25. Theou O, Rockwood MR, Mitnitski A, Rockwood K. Disability and co-morbidity in relation to frailty: how much do they overlap? Arch Gerontol Geriatr. 2012;55(2):e1-8.

26. Ploughman M, Austin MW, Murdoch M, et al. Factors influencing healthy aging with multiple sclerosis: a qualitative study. Disabil Rehabil. 2012;34(1):26-33. 


\begin{tabular}{|c|c|c|c|c|}
\hline \multicolumn{5}{|c|}{$\begin{array}{l}\text { Supplemental Table 1: Performance of admir } \\
\text { multiple sclerosis (MS) as compared to the I } \\
\text { Unit Database }\end{array}$} \\
\hline \multirow[t]{2}{*}{ Characteristics } & \multicolumn{4}{|c|}{ Case Definitions } \\
\hline & 1. $\geq 2 \mathrm{H}$ or $\mathrm{P}$ & 2. $\geq 3 \mathrm{H}$ or $\mathrm{P}$ & 3. $\geq 5 \mathrm{H}$ or $\mathrm{P}$ & 4. $\geq 7 \mathrm{H}$ or $\mathrm{P}$ \\
\hline \multicolumn{5}{|c|}{ A. Possible MS cases classified as MS } \\
\hline $\begin{array}{l}\text { Sensitivity } \\
(95 \% \mathrm{CI}) \\
\text { Specificity } \\
(95 \% \mathrm{CI}) \\
\mathrm{PPV} \\
(95 \% \mathrm{CI}) \\
\mathrm{NPV} \\
(95 \% \mathrm{CI}) \\
\text { Youden's J } \\
(95 \% \mathrm{CI}) \\
\text { Kappa } \\
(95 \% \mathrm{CI}) \\
\end{array}$ & $\begin{array}{c}0.94 \\
(0.93,0.95) \\
0.45 \\
(0.40,0.49) \\
0.91 \\
(0.90,0.92) \\
0.55 \\
(0.50,0.60) \\
0.39 \\
(0.34,0.43) \\
0.42 \\
(0.38,0.47) \\
\end{array}$ & $\begin{array}{c}0.90 \\
(0.89,0.91) \\
0.59 \\
(0.55,0.64) \\
0.93 \\
(0.92,0.94) \\
0.49 \\
(0.45,0.53) \\
0.50 \\
(0.45,0.54) \\
0.46 \\
(0.42,0.50) \\
\end{array}$ & $\begin{array}{c}0.84 \\
(0.82,0.85) \\
0.70 \\
(0.66,0.74) \\
0.95 \\
(0.94,0.96) \\
0.41 \\
(0.37,0.44) \\
0.54 \\
(0.50,0.58) \\
0.41 \\
(0.38,0.45) \\
\end{array}$ & $\begin{array}{c}0.78 \\
(0.77,0.80) \\
0.77 \\
(0.73,0.81) \\
0.96 \\
(0.95,0.96) \\
0.36 \\
(0.33,0.39) \\
0.55 \\
(0.51,0.59) \\
0.37 \\
(0.34,0.41) \\
\end{array}$ \\
\hline \multicolumn{5}{|c|}{ B. Possible MS cases classified as not MS } \\
\hline & 1. $\geq 2 \mathrm{H}$ or $\mathrm{P}$ & 2. $\geq 3$ H or $P$ & 3. $\geq 5 \mathrm{H}$ or $\mathrm{P}$ & 4. $\geq 7 \mathrm{H}$ or $\mathrm{P}$ \\
\hline $\begin{array}{l}\text { Sensitivity } \\
(95 \% \text { CI }) \\
\text { Specificity } \\
(95 \% \text { CI }) \\
\text { PPV } \\
(95 \% \text { CI }) \\
\text { NPV } \\
(95 \% \text { CI) } \\
\text { Youden's J } \\
(95 \% \text { CI }) \\
\text { Kappa } \\
(95 \% \mathrm{CI}) \\
\end{array}$ & $\begin{array}{c}0.98 \\
(0.97,0.98) \\
0.35 \\
(0.32,0.38) \\
0.80 \\
(0.79,0.81) \\
0.86 \\
(0.82,0.89) \\
0.33 \\
(0.30,0.36) \\
0.40 \\
(0.37,0.43) \\
\end{array}$ & $\begin{array}{c}0.95 \\
(0.94,0.96) \\
0.48 \\
(0.45,0.52) \\
0.83 \\
(0.82,0.85) \\
0.79 \\
(0.76,0.82) \\
0.44 \\
(0.41,0.47) \\
0.50 \\
(0.47,0.53) \\
\end{array}$ & $\begin{array}{c}0.90 \\
(0.89,0.92) \\
0.62 \\
(0.59,0.65) \\
0.86 \\
(0.85,0.88) \\
0.71 \\
(0.68,0.74) \\
0.52 \\
(0.49,0.56) \\
0.54 \\
(0.51,0.58) \\
\end{array}$ & $\begin{array}{c}0.86 \\
(0.84,0.87) \\
0.70 \\
(0.67,0.73) \\
0.88 \\
(0.87,0.90) \\
0.65 \\
(0.62,0.67) \\
0.56 \\
(0.53,0.59) \\
0.54 \\
(0.51,0.57) \\
\end{array}$ \\
\hline \multicolumn{5}{|c|}{ C. Possible MS cases removed from analysis } \\
\hline & $1 . \geq 2$ H or $P$ & 2. $\geq 3$ H or $P$ & 3. $\geq 5 \mathrm{H}$ or $\mathrm{P}$ & 4. $\geq 7 \mathrm{H}$ or $\mathrm{P}$ \\
\hline $\begin{array}{l}\text { Sensitivity } \\
(95 \% \text { CI }) \\
\text { Specificity } \\
(95 \% \text { CI }) \\
\text { PPV } \\
(95 \% \text { CI }) \\
\text { NPV } \\
(95 \% \text { CI }) \\
\text { Youden's J } \\
(95 \% \text { CI }) \\
\text { Kappa } \\
(95 \% \text { CI })\end{array}$ & $\begin{array}{c}0.98 \\
(0.97,0.98) \\
0.45 \\
(0.40,0.49) \\
0.90 \\
(0.89,0.91) \\
0.79 \\
(0.74,0.84) \\
0.42 \\
(0.38,0.47) \\
0.51 \\
(0.47,0.56)\end{array}$ & $\begin{array}{c}0.95 \\
(0.94,0.96) \\
0.59 \\
(0.55,0.64) \\
0.93 \\
(0.92,0.94) \\
0.70 \\
(0.66,0.75) \\
0.55 \\
(0.50,0.59) \\
0.58 \\
(0.54,0.62)\end{array}$ & $\begin{array}{c}0.90 \\
(0.89,0.92) \\
0.70 \\
(0.66,0.74) \\
0.94 \\
(0.93,0.95) \\
0.58 \\
(0.54,0.62) \\
0.61 \\
(0.57,0.65) \\
0.56 \\
(0.52,0.60)\end{array}$ & $\begin{array}{c}0.86 \\
(0.84,0.87) \\
0.77 \\
(0.73,0.81) \\
0.95 \\
(0.94,0.96) \\
0.50 \\
(0.47,0.54) \\
0.63 \\
(0.59,0.67) \\
0.52 \\
(0.48,0.55)\end{array}$ \\
\hline
\end{tabular}

$\mathrm{H}=$ hospital claim, $\mathrm{P}=$ physician claim, $\mathrm{PPV}=$ positive predictive value, $\mathrm{NPV}=$ negative predictive value, $\mathrm{CI}=$ confidence interval

\begin{tabular}{|c|c|c|c|c|c|c|c|c|}
\hline \multirow{3}{*}{ Characteristic } & \multicolumn{8}{|c|}{ Case Definitions } \\
\hline & \multicolumn{2}{|c|}{$\geq 2 \mathrm{H}$ or $\mathrm{P}$} & \multicolumn{2}{|c|}{$\geq 3 \mathrm{H}$ or $\mathrm{P}$} & \multicolumn{2}{|c|}{$\geq 5 \mathrm{H}$ or $\mathrm{P}$} & \multicolumn{2}{|c|}{$\geq 7 \mathrm{H}$ or $\mathrm{P}$} \\
\hline & $\begin{array}{l}\leq 3 \mathrm{yrs} \\
\text { of data }\end{array}$ & $\begin{array}{l}>3 \mathrm{yrs} \\
\text { of data }\end{array}$ & $\begin{array}{l}\leq 3 \mathrm{yrs} \\
\text { of data }\end{array}$ & $\begin{array}{l}>3 \mathrm{yrs} \\
\text { of data }\end{array}$ & $\begin{array}{l}\leq 3 \mathrm{yrs} \\
\text { of data }\end{array}$ & $\begin{array}{l}>3 \mathrm{yrs} \\
\text { of data }\end{array}$ & $\begin{array}{l}\leq 3 \mathrm{yrs} \\
\text { of data }\end{array}$ & $\begin{array}{l}>3 \mathrm{yrs} \\
\text { of data }\end{array}$ \\
\hline $\begin{array}{l}\text { Sensitivity } \\
(95 \% \mathrm{CI})\end{array}$ & 0.91 & 0.95 & $\begin{array}{c}0.78 \\
0\end{array}$ & 0.91 & 0.51 & 0.87 & 0.37 & 0.82 \\
\hline Specificity & $\begin{array}{c}(0.87,0.94) \\
0.46\end{array}$ & $\begin{array}{c}(0.94,0.95) \\
0.44\end{array}$ & & $\begin{array}{c}(0.90,0.92) \\
0.59\end{array}$ & $\begin{array}{c}(0.45,0.57) \\
0.89\end{array}$ & $\begin{array}{c}(0.86,0.88) \\
0.69\end{array}$ & $\begin{array}{c}(0.32,0.43) \\
1.00\end{array}$ & $\begin{array}{c}(0.81,0.84) \\
0.75\end{array}$ \\
\hline$(95 \% \mathrm{CI})$ & $(0.29,0.63)$ & $(0.40,0.49)$ & $(0.48,0.81)$ & $(0.55,0.63)$ & $(0.73,0.97)$ & $(0.65,0.73)$ & & $(0.71,0.79)$ \\
\hline PPV & 0.93 & 0.91 & 0.95 & 0.93 & 0.97 & 0.95 & 1.00 & 0.95 \\
\hline$(95 \% \mathrm{CI})$ & $(0.90,0.96)$ & $(0.90,0.92)$ & $(0.91,0.97)$ & $(0.92,0.94)$ & $(0.93,0.99)$ & $(0.94,0.95)$ & & $(0.94,0.96)$ \\
\hline NPV & 0.38 & 0.57 & 0.26 & 0.53 & 0.18 & 0.46 & 0.16 & 0.41 \\
\hline$(95 \% \mathrm{CI})$ & $(0.24,0.54)$ & $(0.52,0.62)$ & $(0.18,0.37)$ & $(0.49,0.57)$ & $(0.13,0.24)$ & $(0.42,0.50)$ & $(0.12,0.22)$ & $(0.38,0.44)$ \\
\hline Youden's J & 0.37 & 0.39 & 0.43 & 0.50 & 0.39 & 0.56 & 0.37 & 0.58 \\
\hline$(95 \% \mathrm{CI})$ & $(0.20,0.54)$ & $(0.35,0.44)$ & $(0.27,0.60)$ & $(0.46,0.55)$ & $(0.27,0.51)$ & $(0.52,0.60)$ & $(0.32,0.43)$ & $(0.54,0.61)$ \\
\hline Kappa & 0.34 & 0.43 & 0.26 & 0.48 & 0.14 & 0.46 & 0.11 & 0.42 \\
\hline
\end{tabular}

$\mathrm{H}=$ hospital claim, $\mathrm{P}=$ physician claim, $\mathrm{PPV}=$ positive predictive value, $\mathrm{NPV}=$ negative predictive value 